\title{
PENGARUH PRICE DISCOUNT DAN BONUS PACK TERHADAP IMPULSE BUYING (STUDI KASUS PADA PELANGGAN ALFAMART DI KOTA JAMBI)
}

\author{
AdeWahyu Ramadhan ${ }^{1)}$, Novita Ekasari ${ }^{2)^{*}}$ \\ ${ }^{1,2)}$ Prodi Manajemen FEB Universitas Jambi \\ *Corresponding author : ekasari.novita01@gmail.com
}

\begin{abstract}
Abstrak
Penelitian ini bertujuan untuk mengetahui: (1) pengaruh price discount terhadap impulse buying pada pelanggan Alfamart (2) pengaruh bonus pack terhadap impulse buying pada pelanggan Alfamart (3) pengaruh paling dominan terhadap impulse buying pada pelanggan Alfamart. Penelitian ini dilakukan pada seluruh pelanggan Alfamart di kota jambi. Penelitian ini termasuk penelitian hubungan dengan menggunakan pendekatan kuantitatif.Populasi pada penelitian ini adalah seluruh pelanggan Alfamart yang berada di Kota Jambi.Teknik pengambilan sampel menggunakan metode purposive sampling dengan jumlah sampel sebanyak 100 orang.Teknik pengumpulan data menggunakan kuesioner secara online yang telah diuji validitas dan reabilitasnya, dan teknik analisis data yang digunakan adalah regresi berganda. Hasil penelitian menunjukkan bahwa (1) terdapat pengaruh positif price discount terhadap impulse buying pada pelanggan Alfamart, dibuktikan dari nilai $t$ hitung sebesar 2,087, signifikansi 0,04<0,05 dan koefisien regresi mempunyai nilai positif sebesar 0,250; (2) terdapat pengaruh positif bonus pack terhadap impulse buying pada pelanggan Alfamart, dibuktikan dari nilai $t$ hitung sebesar 3,556, signifikansi 0,001<0,05 dan koefisien regresi mempunyai nilai positif sebesar 0,426; (3) bonus pack berpengaruh paling dominan terhadap impulse buying dengan nilai koefisien regresi sebesar 0,426 lebih besar dari nilai koefisien regresi price discount sebesar 0,250.
\end{abstract}

Kata Kunci : Price Discount, Bonus Pack, Impulse Buying.

\begin{abstract}
This study aims to determine: (1) the effect of price discount on impulse buying on Alfamart customers (2) the effect of bonus packs on impulse buying on Alfamart customers (3) the most dominant influence on impulse buying on Alfamart customers. This research was conducted on all Alfamart customers in the city of Jambi. This research includes relationship research using a quantitative approach. The population in this study were all Alfamart customers in Jambi City. The sampling technique used purposive sampling method with a total sample of 100 people. The data collection technique uses an online questionnaire that has been tested for validity and reliability, and the data analysis technique used is multiple regression. The results showed that (1) there was a positive effect of price discount on impulse buying for Alfamart customers, as evidenced by the tcount value of 2.087, significance of $0.04<0.05$ and the regression coefficient having a positive value of 0.250 ; (2) there is a positive effect of bonus packs on impulse buying for Alfamart customers, as evidenced by the t-count value of 3.556, a significance of 0.001 $<0.05$ and the regression coefficient has a positive value of 0.426; (3) the bonus pack has the most dominant effect on impulse buying with a regression coefficient value of 0.426 , which is greater than the price discount regression coefficient of 0.250 .
\end{abstract}

Key words : Price Discount, Bonus Pack, Impulse Buying. 


\section{PENDAHULUAN}

Perkembangan bisnis ritel saat ini mengalami peningkatan pesat. Hal tersebutbisa dilihat dari perpindahan bisnis ritel dari tradisional ke modern.Berbagai macam pusat pembelanjaan muncul dengan berbagai bentuk dan ukuran yang ada di sekitar kita. Beberapa contoh bentuk dan ukuran pusatpembelanjaan modern dari yang kecil sampai yang besar seperti departemen store,(swalayan)supermarket, convenience store, dan combination store. Retail adalah semua usaha bisnis yang secara langsung mengarahkan kemampuan pemasarannya untuk memuaskan konsumen akhir berdasarkan organisasi penjualan barang dan jasa sebagai inti dari distribusi (Gilbert 2003:6). Di Bawah ini terdapat data penjualan ritel modern mengalami pertumbuhan setiap tahunnya.

Tabel 1. Data Penjualan Ritel

\begin{tabular}{|c|c|}
\hline Tahun & Penjualan \\
\hline 2016 & Rp. 205.000 .000 .000 \\
\hline 2017 & Rp. 212.000 .000 .000 \\
\hline 2018 & Rp. 233.000 .000 .000 \\
\hline 2019 & Rp. 256.000 .000 .000 \\
\hline
\end{tabular}

Sumber :Asosiasi Pengusaha Ritel Indonesia (Aprindo).

Pesatnya bisnis ritel di Kota Jambi ditunjukkan dengan munculnya usaha ritel kelas minimarket, supermarket, toserba, department store sampai kelas hypermarket berskala nasional (seperti TransMart, Matahari, Lippo, WTC, Ramayana, Jambi Town Square,dan Jambi Prima Mall). Begitupun PT. Sumber Alfaria Trijaya yang mewujudkannya dengan mendirikan Alfamart, bisnis ritel yang termasuk convience store ini memiliki visi "Menjadi jaringan distribusi ritel terkemuka yang dimiliki oleh masyarakat luas, berorientasi kepada pemberdayaan pengusaha kecil, pemenuhan kebutuhan dan harapan konsumen, serta mampu bersaing secara global" dengan moto "Belanja Puas, Harga Pas". Sebagai bagian dari masyarakat, Alfamart berupaya dan berkomitmen untuk memberikan manfaat yang sebanyak mungkin bagi masyarakat di lingkungan sekitar. Pendekatan program-program kegiatan yang dilakukan meliputi aspek community development. Selain itu Alfamart juga mengajak masyarakat untuk ikut terlibat dalam pengembangan sosial kemasyarakatan melalui Program Donasi. Dalam menjalankan program, Alfamart bekerjasama dengan lembaga-lembaga yang terpercaya dan berpengalaman guna mendukung pelaksanaan program.

Price Discount dan Bonus Pack merupakan promosi penjualan yang paling banyak digunakan.Price Discount adalah strategi promosi penjualan berbasis harga di mana pelanggan ditawarkan produk yang sama dengan harga yang lebih murah disbanding harga normalnya, Bonus Pack merupakan strategi promosi penjualan berbasis kuantitas di mana pelanggan ditawarkan produk dengan kuantitas yang lebih dengan harga yang sama (Mishra \& Mishra, 2011). Promo tersebut memungkinkan para peritel memingatkan para pelanggan dan menstimulasi belanja impulsive (Ma'ruf, 2006).

Seperti diketahui Alfamart sering melakukan promo, bermacam-macam promo selalu tersedia di Alfamart. Adapun promo yang ingin peneliti uraiakan antara lain, Price Discount atau biasa disebut potongan harga sering terjadi di Alfamart yang dimana harga produk yang ditentukan akan mendapatkan harga yang lebih murah dari harga normal. Hampir sama dengan Price Discount, Bonus pack sama-sama memiliki potongan harga tapi produk yang akan kita dapatkan lebih dari 1 biasa di sebut buy 1 get 1 . Berdasarkan 
hal diatas penulis tertarik untuk meniliti lebih jauh tentang keterkaitan Price Discount dan Bonus Pack dengan Impulse Buying atau pembelian yang tidak terencana.

Untuk memperkuat pemilihan saya terhadap Alfamart, saya melakukan observasi awal dengan melakukan penyebaran kuesioner secara online melalui Google Form.Inilah hasil dari observasi awal yang telah saya sebar.

\section{Gambar 1. Data hasil observasi awal ritel modern di Indonesia.}
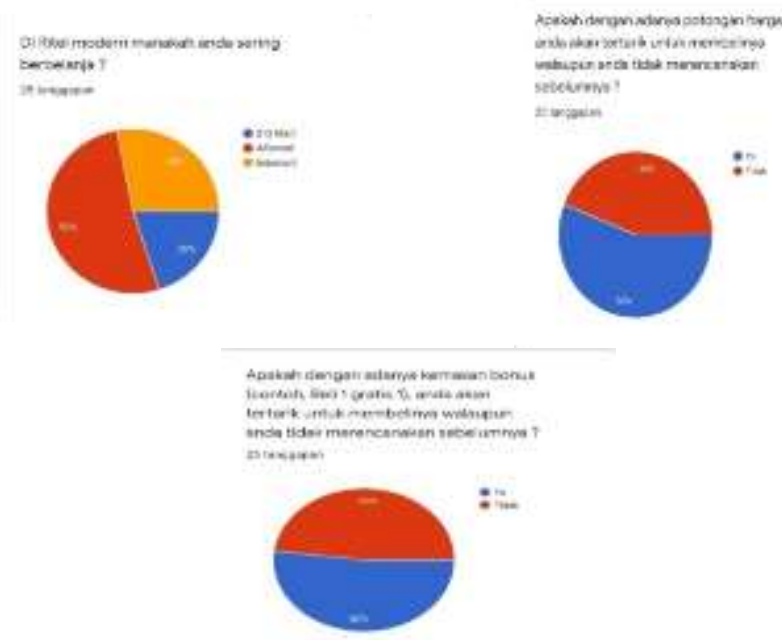

Sumber : Survey Pendahuluan Peniliti (2019)

Responden lebih cenderung berbelanja di Alfamart dibandingkan Indomart dan 212 mart. Alfamart sendiri memiliki banyak cabang yang tersebar di seluruh kota Jambi, hal itu bisa dilihat dari tabel dibawah ini :

Tabel 2. Jumlah Ritel Modern di Kota Jambi

\begin{tabular}{|c|c|c|}
\hline No. & Nama Minimarket Modern & Jumlah Cabang \\
\hline 1 & 212 mart & 3 \\
\hline 2 & Alfamart & 99 \\
\hline 3 & Indomaret & 43 \\
\hline & Total & 145 \\
\hline \multicolumn{2}{|c|}{ Sumber : Survey Pendahuluan Peniliti (2019) } \\
\hline
\end{tabular}

Penelitian ini memfokuskan kepada seluruh masyarakat Kota Jambi yang pernah belanja di Alfamart. Data seluruh penduduk di Kota Jambi yang terbagi dari beberapa kecamatan :

Tabel 3. Nama kecamatan,Ibukota kecamatan, Jumlah Penduduk dan Kelurahan di Kota Jambi 2018

\begin{tabular}{|c|c|c|c|c|}
\hline No. & Kecamatan & Ibukota & Jumlah Penduduk & Jumlah Kelurahan \\
\hline 1 & Kota baru & Paal V & 75.384 & 5 \\
\hline 2 & Jambi selatan & Thehok & 61.743 & 5 \\
\hline 3 & Jelutung & Jelutung & 63.369 & 7 \\
\hline 4 & Pasar Jambi & Pasar Jambi & 12.532 & 4 \\
\hline 5 & Telanaipura & Telanaipura & 50.482 & 5 \\
\hline 6 & Danau Teluk & Olak kemang & 12.083 & 6 \\
\hline 7 & Pelayangan & Pelayangan & 13.585 & 6 \\
\hline 8 & Jambi Timur & Tanjung Pinang & 66.709 & 9 \\
\hline 9 & Alam Barajo & Beliung & 99.329 & 5 \\
\hline 10 & Danau Sipin & Murni & 48.689 & 5 \\
\hline \multicolumn{5}{|r}{} \\
\hline
\end{tabular}




\begin{tabular}{|c|c|c|c|c|}
\hline 11 & Paalmerah & Talang Bakung & 89.835 & 5 \\
\hline \multicolumn{3}{|c|}{ Jumlah } & 593.740 & 62 \\
\hline
\end{tabular}

Sumber : Provinsi Jambi dalam angka edisi 2018

\section{Rumusan Masalah}

1. Apakah Terdapat pengaruh Price Discount dan Bonus Pack secara Simultan dan Parsial terhadap Impluse Buying Pelanggan?

2. Variabel manakah dari Price Discount dan Bonus Pack yang paling dominan terhadap Impulse BuyingPelanggan?

\section{Tujuan Penelitian}

1. Pengaruh Price Discount dan Bonus Pack secara Simultan dan Parsial terhadap Impulse Buying terhadap Pelanggan.

2. Variabel yang paling dominan terhadap Impulse Buying Pelanggan

\section{TINJAUAN LITERATUR}

\section{Price Discount}

Belch \& Belch (2009) mengatakan bahwa Price Discount memberikan beberapa keuntungan diantaranya: dapat memicu konsumen untuk membeli dalam jumlah yang banyak, mengantisipasi promosi pesaing, dan mendukung perdagangan dalam jumlah yang lebih besar. Menurut Tjiptono (2008:166) Diskon merupakan potongan harga yang diberikan oleh penjual kepada pembeli sebagai penghargaan atas aktivitas tertentu dari pembeli yang menyenangkan bagi penjual.

\section{Bonus Pack}

Menurut Belch dan Belch dalam Amanda (2014) Bonus Pack menawarkan konsumen sebuah muatan ekstra dari sebuah produk dengan harga normal. Clow dan Baack dalam Waani (2015:422), menyatakan bahwa ketika jumlah tambahan ditempatkan dalam paket produk khusus,itu adalah paket bonus. Gardener dan Trivedi (1998), menyatakan bahwa paket bonus yang ditawarkan oleh produsen menambah nilai produk dengan menawarkan jumlah tambahan dari produk atau unit dengan harga biasa.

\section{Impulse Buying}

Solomon \& Rabolt (2009) menyatakan bahwa impulse buying adalah suatu kondisi yang terjadi ketika individu mengalami perasaan terdesak secara tiba-tiba yang tidak dapat dilawan. Kecenderungan untuk membeli secara spontan ini umumnya dapat menghasilkan pembelian ketika konsumen percaya bahwa tindakan tersebut adalah hal yang wajar (Rook \& Fisher 1995 dalam Solomon 2009).

\section{Kerangka Pemikiran}

\section{Pengaruh Price Discount terhadap Impulse Buying}

Menurut Kotler (2003) price discount, merupakan penghematan yang ditawarkan pada konsumen dari harga normal akan suatu produk, yang tertera di label atau kemasan produk tersebut. Belch \& Belch (2009) mengatakan bahwa promosi potongan harga memberikan beberapa keuntungan diantaranya : dapat memicu konsumen untuk membeli dalam jumlah yang banyak, mengantisipasi promosi pesaing, dan mendukung perdagangan dalam jumlah yang lebih besar.

Dari definisi di atas dapat dinyatakan bahwa price discount diciptakan untuk meningkatkan penjualan suatu produk yang mengalami penurunan dan mendorong konsumen melakukan pembelian coba-coba. Untuk memperoleh konsumen dengan jumlah yang banyak produsen memaksimalkan keuntungan jangka pendek dengan cara memberi 
penawaran price discount. Hasil studi Putri, Y.T.A. dan Edwar, M., (2014) tentang "Pengaruh Bonus Pack dan Price Discount Terhadap Impulse Buying pada Konsumen Giant Hypermarket Diponegoro Surabaya" menunjukan bahwa variabel price discount berpengaruh secara individual dan signifikan terhadap impulse buying.

\section{Pengaruh Bonus Pack terhadap Impulse Buying}

Menurut Belch \& Belch (2009) bonus pack menawarkan konsumen sebuah muatan ekstra dari sebuah produk dengan harga normal. Menurut Mishra \& Mishra (2011) bonus pack merupakan strategi promosi penjualan berbasis kuantitas di mana pelanggan ditawarkan produk dengan kuantitas lebih dengan harga yang sama, sedangkan Jullian Cummins (2001 : 114 ) mendefisinikan bonus pack adalah tawaran dengan manfaat ekstra dimana manfaat ekstra tersebut berbentuk suatu barang dagangan.

Berdasarkan uraian tersebut maka dapat dibuat suatu kerangka pemikiranuntuk menggambarkan hubungan antara variabel independent yaitu Price discount dan Bonus pack terhadap variabel dependen yaitu Impulse Buying.

Gambar 2.1

Kerangka Pemikiran

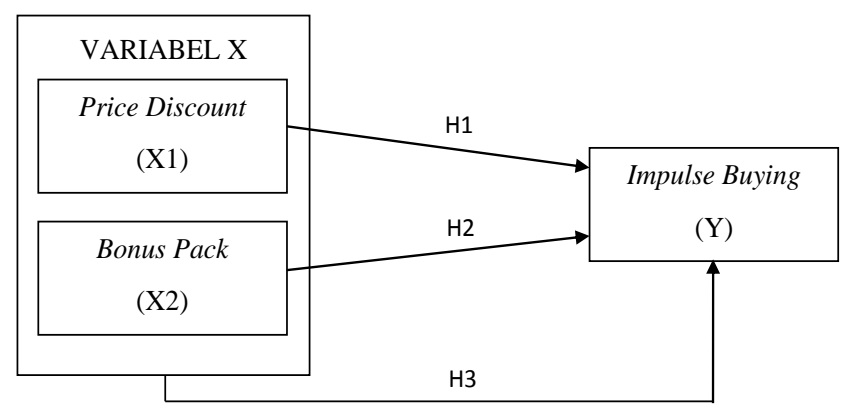

\section{Hipotesis}

Berdasarkan kerangka pikir tersebut, maka hipotesis dalam penelitian dapat dirumuskan sebagai berikut:

H1 : Price Discount berpengaruh signifikan dan positif terhadap Impulse Buying secara simultan dan parsial.

H2: Bonus Pack berpengaruh signifikan dan positif terhadap Impulse Buying secara simultan dan parsial.

H3 : Bonus Pack merupakan variable yang berpengaruh paling dominan terhadap Impulse Buying.

\section{METODE PENELITIAN}

\section{Desain Penelitian}

Penelitian ini menggunakan pendekatan kuantitatif. Metode survei dipilih sebagai sumber data primer. Metode survei yang dilakukan fokus pada pengumpulan data responden yang memiliki informasi tertentu sehingga memungkinkan peneliti untuk menyelesaikan masalah. Pengumpulan data dilakukan menggunakan instrument kuesioner atau angket. Berdasarkan tingkat eksplanasinya, penelitian ini tergolong sebagai penelitian asosiatif atau hubungan, yaitu penelitian untuk mengetahui sebab akibat. Hubungan atau pengaruh variabel bebas (X) terhadap variabel terikat(Y) (Sugiyono, 2012). 


\section{Teknik Pengumpulan Data}

Teknik pengumpulan data untuk mendapatkan data-data ataupun informasi yang dibutuhkan dalam penelitian ini, maka peneliti menggunakan dua teknik pengumpulan data yaitu data primer dan skunder.

\section{Populasi dan Sampel}

Dalam penelitian ini, populasi mengacu pada seulurh pelanggan Alfamart yang sedang berbelanja ataupun setelah belanja di Kota Jambi.

Sample adalah bagian dari jumlah dan karakteristik yang dimiliki oleh populasi tersebut.(sugiyono,2012). Dalam penelitian ini penulis menkriteriakan responden yang sesuai untuk mendukung penelitian ini. Maka dari itu, sampel yang di ambil harus betulbetul mewakili (representetif) dari populasi tersebut. Untuk menentukan unit sampel yang akan digunakan dalam penelitian, maka digunakan rumus Slovin. Maka diperoleh jumlah sample sebanyak 100 responden yang merupakan pelanggan Alfamart.

\section{Metode Analisis Data}

Instrumen utama yang digunakan dalam penelitian ini untuk menggunakan data adalah menggunakan kuesioner yang disusun secara sistematis berisikan beberapa pernyataan yang diberikan kepada responden. Dengan menggunakan alat ukur yang valid dan reliable dalam pengumpulan data, diharapkan hasil penelitian akan menjadi valid dan reliable. Pengujian validitas dan reliabel dilakukan dengan menggunakan bantuan komputer yaitu SPSS for windows.

\section{Regresi Linear Berganda}

Analisis regresi pada dasarnya adalah studi mengenai ketergantungan variabel dependen (terikat) dengan satu atau lebih variabel independen (variabel penjelas atau bebas), dengan tujuan untuk mengestimasi rata-rata populasi atau nilai rata-rata variabel dependen berdasarkan nilai variabel independen yang diketahui (Gujarati, 2003). Analisis regresi berganda dalam penelitian ini bertujuan untuk mengetahui besarnya pengaruh variabel independen (price discount dan bonus pack) terhadap variabel dependen (impulse buying). Adapun bentuk umum persamaan regresi berganda yang digunakan dalam penelitian ini adalah sebagai berikut.Persamaan regresi linier berganda sebagai berikut:

Dimana:

$$
\mathbf{Y}=\mathbf{a}+\mathbf{b}_{1} \mathbf{X}_{1}+\mathbf{b}_{2} \mathbf{X}_{2}+\mathbf{e}
$$

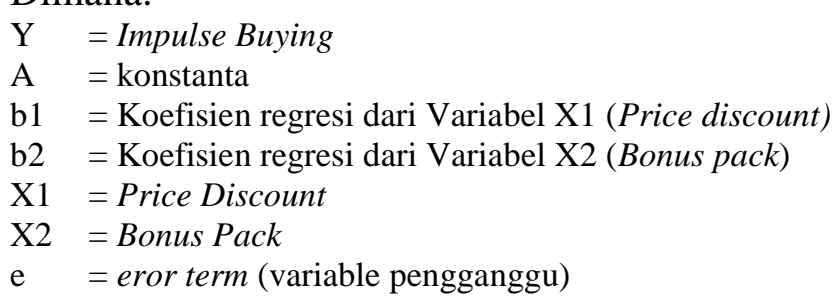

\section{Analisis Deskriptif}

Analisis deskriptif pada penelitian ini merupakan uraian atau penjelasan dari hasil pengumpulan data primer berupa kuesioner yang telah diisi oleh responden. Analisis deskriptif digunakan untuk mendeskripsikan data yang sudah di miliki yaitu data variabel bebas (independent) dan variabel terikat (dependent). Dimana variabel bebas Price Discount (Potongan Harga) dan Bonus Pack (Muatan Extra) dan variabel terikat adalah Impulse Buying disajikan dalam bentuk table, diagram, dan berbagai bentuk lainnya dengan uraian singkat dan jelas. 


\section{Karakteristik Responden}

Karakteristik responden yang diamati dalam penelitian ini meliputi: jenis kelamin, usia, tingkat pendidikan terakhir dan penghasilan perbulan. Dari hasil data yang telah terkumpul, jumlah responden berdasarkan jenis kelamin laki-laki yaitu 58 orang dengan persentase $58 \%$.sedangkan yang berjenis kelamin perempuan berjumlah 42 orang dengan persentase $42 \%$.

Responden yang berumur dari 20-25 tahun berjumlah 41 responden dengan persentase $41 \%$, untuk yang berumur 25-29 tahun berjumlah 27 responden dengan persentase $27 \%$, untuk umur 30-35 tahun berjumlah 17 responden dengan persentase $17 \%$, dan terakhir responden berusia $>35$ tahun berjumlah 15 responden dengan persentase $15 \%$.

Dari hasil kuesioner yang diperoleh berdasarkan pendidikan terakhir menunjukkan responden yang memiliki tingkat pendidikan terakhir SMA/SMK berjumlah 50 responden dengan persentase 50\% dan yang menempuh Perguruan Tinggi berjumlah 50 responden dengan persantase $50 \%$.

Kemudian yang terakhir dari data penyebaran kuesioner menunjukkan Terdapat 30 responden yang berpendapatan $<\mathrm{Rp} .1 .000 .000$ dengan persentase $30 \%$, sedangkan yang berpendapatan Rp. 1.000.000 - Rp.5.000.000 berjumlah 38 responden dengan persentase $38 \%$ dan yang berpendapatan Rp.5.000.000 - Rp. 10.000 .000 berjumlah 25 responden dengan persentase $25 \%$ dan yang terakhir yang berpendapatan $>$ Rp. 10.000 .000 berjumlah 7 responden dengan persentase $7 \%$.

\section{Pengujian Instrumental}

Sebelum penelitian, terlebih dahulu kuesioner diujicobakan untuk mengetahui tingkat validitas dan reliabilitasnya dengan menyebarkan kuesioner sebanyak 30 eksemplar.

\section{Uji Validitas}

Hasil uji validitas kuesioner dapat dilihat pada tabel berikut.

Tabel 4. Hasil Uji Validitas Responden

\begin{tabular}{|c|c|c|c|c|}
\hline Variabel & No Butir & Person Correlation & $\begin{array}{c}\text { rTabel } \\
(10 \%)\end{array}$ & $\begin{array}{c}\text { Hasil } \\
\text { Validitas }\end{array}$ \\
\hline \multirow{3}{*}{ Price Discount } & X1.1 & 0,679 & 0,296 & Valid \\
(X1) & X1.2 & 0,824 & 0,296 & Valid \\
& X1.4 & 0,830 & 0,296 & Valid \\
& X1.5 & 0,724 & 0,296 & Valid \\
& X2.1 & 0,696 & 0,296 & Valid \\
\hline \multirow{3}{*}{ Bonus Pack } & X2.2 & 0,723 & 0,296 & Valid \\
(X2) & X2.3 & 0,837 & 0,296 & Valid \\
& X2.5 & 0,731 & 0,296 & Valid \\
Impulse Buying & Y1 & 0,794 & 0,296 & Valid \\
(X3) & Y2 & 0,734 & 0,296 & Valid \\
\hline & Y3 & 0,535 & 0,296 & Valid \\
& Y4 & 0,817 & 0,296 & Valid \\
& Valid \\
\hline
\end{tabular}

Sumber : data primer diolah (2020)

Uji validitas digunakan untuk mengetahui sejauh mana alat ukur dapat digunakan secara tepat terhadap gejala yang diukur. Hasil uji validitas menunjukkan nilai Pearson Correlation lebih dari 0,296 maka semua butir valid atau benar dalam mengukur gejala 
yang diukur dalam hal ini variabel price discount $\left(\mathrm{X}_{1}\right)$, bonus pack $\left(\mathrm{X}_{2}\right)$, dan impulse buying (Y).

\section{Uji Reliabilitas}

Pengujian reliabilitas bertujuan untuk memberikan hasil yang dapat diandalkan secara empiris dan dapat mengurangi tingkat kesalahan pada alat ukur.Hasil uji reliabilitas instrumen (30 responden) dapat dilihat pada tabel berikut ini.

Tabel 5. Hasil Uji Reliabilitas Responden

\begin{tabular}{|c|c|c|c|l|l|}
\hline \multirow{2}{*}{ Variabel } & \multirow{2}{*}{ No Butir } & \multicolumn{2}{|l|}{ Croncbach's Alpha } & rTabel & Ket. \\
\cline { 3 - 6 } & & Per Butir & Per Variabel & $(10 \%)$ & \\
\hline \multirow{3}{*}{ Price Discount } & X1.1 & 0,788 & & 0,296 & Reliabel \\
(X1) & X1.2 & 0,744 & & 0,296 & Reliabel \\
& X1.3 & 0,730 & 0,805 & 0,296 & Reliabel \\
& X1.5 & 0,779 & & 0,296 & Reliabel \\
& X2.1 & 0,792 & & 0,296 & Reliabel \\
\hline \multirow{3}{*}{ Bonus Pack } & X2.2 & 0,827 & & 0,296 & Reliabel \\
(X2) & X2.3 & 0,775 & 0,834 & 0,296 & Reliabel \\
& X2.4 & 0,824 & & 0,296 & Reliabel \\
X2.5 & 0,791 & & 0,296 & Reliabel \\
& Y.1 & 0,416 & & 0,296 & Reliabel \\
\hline \multirow{2}{*}{ Impulse Buying } & Y.2 & 0,598 & & 0,296 & Reliabel \\
(Y) & Y.3 & 0,635 & 0,580 & 0,296 & Reliabel \\
& Y.4 & 0,307 & & 0,296 & Reliabel \\
\hline
\end{tabular}

Sumber : data primer diolah (2020)

Hasil uji reliabilitas menunjukkan bahwa nilai koefisien reliabilitas Cronbach's Alpha baik per butir maupun per variabel lebih dari 0,296.Oleh karena itu, kuesioner yang digunakan dalam uji coba ini reliabel atau dapat diandalkan.

\section{Uji Asumsi Klasik}

Analisis data dilakukan dengan menggunakan analisis regresi. Sebelum melakukan analisis data untuk mencari pengaruh antar variabel yang dipakai untuk penelitian, dilakukan uji asumsi yaitu uji normalitas, uji linearitas, uji multikolinearitas, dan uji heteroskedastisitas.Pelaksananan uji prasyarat analisis dilakukan dengan SPSS 23.

\section{Uji Normalitas}

Uji normalitas dilakukan untuk mengetahui data variabel penelitian berdistribusi normal atau tidak. Pengujian normalitas menggunakan teknik analisis KolmogorovSmirnov (K-S). Hasil uji normalitas untuk variabel penelitian disajikan berikut ini :

Tabel 6. Uji Normalitas

\begin{tabular}{|l|r|r|}
\hline \multicolumn{2}{|c|}{ One-Sample Kolmogorov-Smirnov Test } \\
\hline & & $\begin{array}{c}\text { Unstandardized } \\
\text { Residual }\end{array}$ \\
\hline N & & 100 \\
Normal Parameters & Mean & .0000000 \\
& Std. Deviation & 2.47788436 \\
Most Extreme Differences & Absolute & .090 \\
& Positive & .071 \\
& Negative & -090 \\
Kolmogorov-Smirnov Z & & 900 \\
Asymp. Sig. (2-tailed) & .392 \\
\hline a. Test distribution is Normal. & \\
Sumber : data primer diolah (2020) &
\end{tabular}


Berdasarkan tabel diatas, diketahui bahwa nilai statistik uji Kolmogorov-Smirnov menunjukkan nilai Asymp. Sig (2-tailed) sebesar 0,392 lebih besar dari 0,05 sehingga dapat diketahui bahwa variabel berdistribusi normal.

\section{Uji Multikolinieritas}

Uji multikolinearitas dilakukan untuk mengetahui besarnya interkorelasi antar variabel bebas dalam penelitian ini.Jika terjadi korelasi, maka dinamakan terdapat masalah multikolinearitas. Hasil uji multikolineritas untuk variabel penelitian disajikan berikut ini :

\section{Tabel 7 Hasil Uji Multikolinieritas}

Tabel 5.8

Hasil Uji Multikolinieritas

Coefficients $^{\mathbf{a}}$

\begin{tabular}{|c|c|c|c|c|c|c|c|c|}
\hline & & \multicolumn{2}{|c|}{$\begin{array}{c}\text { Unstandardized } \\
\text { Coefficients }\end{array}$} & \multirow{2}{*}{$\begin{array}{c}\text { Standardized } \\
\text { Coefficients }\end{array}$} & \multirow[b]{2}{*}{$\mathrm{t}$} & \multirow[b]{2}{*}{ Sig. } & \multicolumn{2}{|c|}{$\begin{array}{l}\text { Collinearity } \\
\text { Statistics }\end{array}$} \\
\hline \multicolumn{2}{|c|}{ Model } & B & $\begin{array}{l}\text { Std. } \\
\text { Error }\end{array}$ & & & & Tolerance & VIF \\
\hline \multirow[t]{3}{*}{1} & (Constant) & 2.239 & 1.682 & & 1.331 & .186 & & \\
\hline & TotalX1 & .253 & .121 & .250 & 2.087 & .040 & -428 & 2.337 \\
\hline & TotalX2 & .386 & 109 & .426 & 3.556 & .001 & .428 & 2.337 \\
\hline \multicolumn{3}{|c|}{$\begin{array}{l}\text { a. Dependent Variable: } \\
\text { TotalY }\end{array}$} & & & & & & \\
\hline
\end{tabular}

Dari tabel di atas terlihat bahwa semua variabel mempunyai nilai toleransi $>0,1$ dan nilai VIF $<10$, sehingga dapat disimpulkan bahwa model regresi pada penelitian ini tidak terjadi multikolinearitas.

1. Price Discount mempunyai nilai tolerance 0,428 lebih besar dari 0,1 dan nilai VIF 2,377 lebih kecil dari 10 sehingga variable dalam penelitian ini tidak terjadi multikolinieritas.

2. Bonus Pack mempunyai nilai tolerance 0,428 lebih besar dari 0,1 dan nilai VIF 2,377 lebih kecil dari 10 sehingga variable dalam penelitian ini tidak terjadi multikolinieritas.

\section{Uji heterokedastisitas}

Pengujian heterokedastisitas bertujuan untuk menguji apakah dalam model regresi terjadi ketidaksamaan variance dari residual satu pengamatan ke pengamatan yang lain. Model regresi yang baik adalah tidak terjadi heterokedastisitas dan untuk mengetahui adanya heterokedastisitas dengan menggunakan uji Glejser. Berikut ini adalah hasil uji heterokedastisitas terhadap model regresi pada penelitian ini :

Tabel 8. Hasil Uji Heterokedastisitas

Coefficients $^{\text {a }}$

\begin{tabular}{|c|c|c|c|c|c|}
\hline \multirow[b]{2}{*}{ Model } & \multicolumn{2}{|c|}{$\begin{array}{c}\text { Unstandardized } \\
\text { Coefficients }\end{array}$} & \multirow{2}{*}{$\frac{\text { Standardized Coefficients }}{\text { Beta }}$} & \multirow[b]{2}{*}{$\mathrm{t}$} & \multirow[b]{2}{*}{ Sig. } \\
\hline & B & Std. Error & & & \\
\hline 1 (Constant) & 1.747 & .906 & & 1.928 & .057 \\
\hline TotalX1 & -.007 & .065 & -.017 & -.109 & .914 \\
\hline TotalX2 & .024 & .059 & .063 & .404 & .687 \\
\hline
\end{tabular}

a. Dependent Variable: RES2

Sumber : data priemer diolah (2020) 
Tabel di atas menunjukkan bahwa semua variabel mempunyai nilai signifikansi lebih besar dari > 0,05 sehingga dapat disimpulkan bahwa model regresi pada penelitian ini tidak terjadi heterokedastisitas.

1. Price discount mempunyai nilai signifikansi 0,914 lebih besar dari 0,05 sehingga tidak terjadi heterokedastisitas

2. Bonus Pack mempunyai nilai signifikansi 0,687 lebih besar dari 0,05 sehingga tidak terjadi heterokedastisitas

\section{Pengujian Hipotesis}

Pengujian hipotesis dalam peneitian bertujuan untuk membuktikan pengaruh pengaruh price discount dan bonus pack terhadap impulse buying pada pelanggan minimarket Alfamart di Kota Jambi.Analisis data yang digunakan dalam pengujian hipotesis penelitian ini adalah analisis regresi berganda. Berikut ini akan dibahasa hasil analisis regresi berganda yang dilakukan dengan SPSS 23.

\section{Uji Analisis Regresi Linear}

Hasil analisis regresi linear berganda yang dilakukan dengan menggunakan program SPSS 23 disajikan sebagai berikut :

Tabel 9. Hasil Analisis Regresi Berganda Coefficients $^{\mathbf{a}}$

\begin{tabular}{|l|r|r|r|r|r|}
\hline \multirow{2}{*}{ Model } & \multicolumn{2}{|c|}{ Unstandardized Coefficients } & Standardized Coefficients & \multirow{2}{*}{ Sig. } \\
\cline { 2 - 6 } & \multicolumn{1}{c|}{$\mathrm{B}$} & Std. Error & Beta & \multicolumn{1}{c|}{ Sig } \\
\hline 1(Constant) & 2.239 & 1.682 & & 1.331 & .186 \\
TotalX1 & .253 & .121 & .250 & 2.087 & .040 \\
TotalX2 & .386 & .109 & .426 & 3.556 & .001 \\
\hline
\end{tabular}

a. Dependent Variable: TotalY

Sumber : data primer diolah (2020)

Dari hasil analisis regresi dapat diketahui persamaan regresi berganda sebagai berikut:

$$
Y=2,239+0,253 X 1+0,386 X 2
$$

Berdasarkan persamaan tersebut, maka dapat dijelaskan sebagai berikut:

1. Nilai konstanta sebesar 2,239 dapat diartikan apabila variabel price discount dan bonus pack dianggap nol, maka besarnya impulse buying pelanggan Alfamart adalah positif 2,239 .

2. Nilai koefisien beta pada variabel price discount sebesar 0,253, artinya setiap peningkatan variabel price discount (X1) sebesar satu satuan maka impulse buying meningkat sebesar 0,253, dengan asumsi-asumsi yang lain adalah tetap. Sebaliknya penurunan satu satuan pada variabel price discount akan menurunkan impulse buying pelanggan Alfamart sebesar 0,253.

3. Nilai koefisien beta pada variabel bonus pack sebesar 0,386 , artinya setiap peningkatan variabel bonus pack (X2) sebesar satu satuan maka impulse buying meningkat sebesar 0,386 , dengan asumsi-asumsi yang lain adalah tetap. Sebaliknya penurunan satu satuan pada variabel bonus pack akan menurunkan impulse buying pelanggan Alfamart sebesar 0,386.

Selanjutnya untuk mengetahui apakah hipotesis yang diajukan dalam penelitian ini diterima atau ditolak maka akan dilakukan uji hipotesis dengan menggunakan uji t dan uji F. Hasil pengujian yang telah dilakukan yaitu sebagai berikut : 


\section{Uji t}

Uji t digunakan untuk mengetahui pengaruh satu variabel bebas menjelaskan variabel terikat. Jika nilai signifikansi lebih kecil dari 0,05 (sig<0,05), dapat disimpulkan bahwa variabel bebas secara parsial berpengaruh signifikan terhadap variabel terikat. Penjelasan hasil uji t dari setiap variabel bebas yaitu sebagai berikut:

Tabel 10. Uji t

Coefficients $^{\mathrm{a}}$

\begin{tabular}{|l|r|r|r|r|r|}
\hline \multirow{2}{*}{ Model } & \multicolumn{2}{|c|}{$\begin{array}{l}\text { Unstandardized } \\
\text { Coefficients }\end{array}$} & & \\
\cline { 2 - 5 } & \multicolumn{1}{|c|}{ S } & Standardized Coefficients & & \\
\hline 1 (Constant) & 2.239 & 1.682 & Beta & \multicolumn{1}{c|}{ Sig. } \\
\hline TotalX1 & .253 & .121 & & 1.331 & .186 \\
TotalX2 & .386 & .109 & .250 & 2.087 & .040 \\
\end{tabular}

a. Dependent Variable: totally

Sumber: data primer diolah (2020)

Dari hasil tersebut uji t tersebut maka dapat disimpulkan :

1. Price Discount

Hasil statistik uji t untuk variabel price discount yaitu diperoleh nilai t hitung sebesar 2,087 lebih besar dari nilai t table 1,9847 (2,087>1,9847), nilai signifikansi sebesar 0,040 lebih kecil dari $0,05(0,000<0,05)$, dan koefisien regresi mempunyai nilai positif sebesar 0,250. Maka Price Discount berpengaruh secara parsial terhadap Impulse Buying.

2. Bonus Pack

Hasil statistik uji t untuk variabel bonus pack yaitu diperoleh nilai $\mathrm{t}$ hitung sebesar 3,556 lebih besar dari nilia t table 1,9847 (3,556>1,9847), nilai signifikansi sebesar 0,001 lebih kecil dari $0,05(0,001<0,05)$, dan koefisien regresi mempunyai nilai positif sebesar 0,426. Maka Bonus Pack berpengaruh secara parsial terhadap Impulse buying.

\section{Uji f}

Analisis regresi berganda dengan uji F (Fisher) bertujuan untuk mengetahui pengaruh semua variabel meliputi : price discount dan bonus pack terhadap impulse buying pada pelanggan Alfamart.

Tabel 11. Uji F

ANOVA ${ }^{\mathrm{a}}$

\begin{tabular}{|ll|r|r|r|c|c|}
\hline \multicolumn{1}{|c|}{ Model } & Sum of Squares & df & Mean Square & F & Sig. \\
\hline $1 \quad$ Regression & 413.309 & 2 & 206.654 & 32.978 & $.000^{\mathrm{b}}$ \\
Residual & 607.851 & 97 & 6.267 & & \\
Total & 1021.160 & 99 & & & \\
\hline
\end{tabular}

a. Dependent Variable: totally

b. Predictors: (Constant), TotalX2, TotalX1

Sumber : data primer diolah (2020)

Dari hasil uji $\mathrm{F}$ diperoleh nilai $\mathrm{F}$ hitung sebesar 32,978 lebih besar dari nilai $\mathrm{F}$ table 3,09 $(32,978>3,09)$ dengan signifikansi sebesar 0,000. Oleh karena nilai signifikansi lebih kecil dari 0,05 $(0,000<0,05)$. Maka Price Discount dan Bonus Pack memiliki pengaruh signifikan secara simultan terhadap Impulse Buying. 


\section{Koefisien Deteminasi (Adjusted $R^{2}$ )}

Koefisien determinasi merupakan suatu alat pengukur besarnya pengaruh variabel bebas terhadap variabel terikat.

Tabel 12. Koefisien Determinasi (Adjusted R2) Model Summary

\begin{tabular}{|l|c|r|r|r|}
\hline Model & R & R Square & Adjusted R Square & Std. Error of the Estimate \\
\hline 1 & .636 & .405 & .392 & 2.503 \\
\hline
\end{tabular}

a. Predictors: (Constant), TotalX2, TotalX1

Sumber : data primer diolah (2020)

Hasil uji AdjustedR ${ }^{2}$ pada penelitian ini diperoleh nilai sebesar 0,392. Hal ini menunjukkan bahwa impulse buying pada pelanggan minimarket Indomaret dipengaruhi oleh price discount dan bonus pack sebesar $39,2 \%$, sedangkan sisanya $60,8 \%$ dipengaruhi oleh faktor lain yang tidak termasuk dalam penelitian ini.

\section{PEMBAHASAN}

Penelitian ini bertujuan untuk mengetahui pengaruh price discount dan bonus pack terhadap impulse buying pada pelanggan minimarket Alfamart. Pembahasan masingmasing variabel akan disajikan sebagai berikut:

\section{Price Discount berpengaruh signifikan dan positif terhadap Impulse Buying secara simultan dan parsial.}

Hasil uji statistik yang telah dilakukan menunjukkan adanya pengaruh signifikan dan positif price discount terhadap impulse buying pada pelanggan Alfamart. Hal ini diperoleh dari hasil statistik uji regresi dengan nilai $\mathrm{F}$ hitung sebesar 32,978 lebih besar dari nilai $\mathrm{F}$ table 3,09 (32,978>3,09) dengan signifikansi sebesar 0,000. Oleh karena nilai signifikansi lebih kecil dari $0,05(0,000<0,05)$, t hitung sebesar 2,087 lebih besar dari nilai t table $1,9847(2,087>1,9847)$, dengan nilai signifikansi sebesar 0,040 lebih kecil dari 0,05 $(0,040<0,05)$, dan koefisien regresi mempunyai nilai positif sebesar 0,250 ; maka hipotesis pertama dalam penelitian ini terbukti yaitu "Price Discount (X1) berpengaruh signifikan dan positif terhadap Impulse Buying secara simultan dan parsial (Y)".

\section{Bonus Pack berpengaruh signifikan dan positif terhadap Impulse Buying secara simultan dan parsial.}

Hasil uji statistik yang telah dilakukan menunjukkan adanya pengaruh signifikan dan positif bonus packterhadap impulse buying pada pelanggan Alfamart. Hal ini diperoleh dari hasil statistik uji regresi dengan nilai $\mathrm{F}$ hitung sebesar 32,978 lebih besar dari nilai $\mathrm{F}$ table 3,09 (32,978>3,09) dengan signifikansi sebesar 0,000. Oleh karena nilai signifikansi lebih kecil dari $0,05(0,000<0,05)$, t hitung sebesar 3,556 lebih besar dari nilai t table $1,9847(3,556>1,9847)$, dengan nilai signifikansi sebesar 0,001 lebih kecil dari 0,05 $(0,001<0,05)$, dan koefisien regresi mempunyai nilai positif sebesar 0,426 ; maka hipotesis kedua dalam penelitian ini terbukti yaitu "Bonus Pack (X2) berpengaruh signifikan dan positif terhadap Impulse Buying secara simultan dan parsial (Y)".

\section{Bonus Pack merupakan variable yang berpengaruh paling dominan terhadap Impulse Buying.}

Hasil uji statistic yang telah dilakukan menunjukkan bahwa variabel Bonus Pack merupakan variabel yang berpengaruh paling dominan dibandingkan variabel Price Discount.Bonus Pack mempunyai nilai koefisien regresi positif sebesar 0,426 lebih besar dibandingkan Price Discount yang memiliki nilai koefisien regresi positif sebesar 0,250 ; 
maka hipotesis ketiga dalam penelitian ini terbukti yaitu "Bonus Pack merupakan variable yang berpengaruh paling dominan terhadap Impulse Buying."

\section{SIMPULAN DAN SARAN}

\section{Simpulan}

1. Terdapat pengaruh signifikan dan positif price discount terhadap Impulse Buying baik secara simultan dan parsial. Hasil ini bisa dilihat dari nilai koefisien beta dari variabel price discount terhadap impulse buying, setiap perubahan nilai dari variabel price discount mempengaruhi impulse buying.

2. Terdapat pengaruh signifikan dan positif bonus pack terhadap impulse buying baik secara simultan dan parsial. Hasil ini bisa dilihat dari nilai koefisien beta dari variabel bonus pack terhadap impulse buying, setiap perubahan nilai dari variabel bonus pack mempengaruhi impulse buying.

3. Bonus pack merupakan variabel paling dominan terhadap impulse buying, bonus pack memiliki nilai koefisien beta paling tinggi dibandingkan price diskon. Hasil ini bisa dilihat dari tabel regresi linear.

\section{Saran}

Bentuk promosi Price discount dan Bonus Pack yang ada di Alfamart dapat mempengaruhi pembelian secara impulsif (impulse buying). Perlu memfokuskan peningkatan kualitas dari promo price discount yang dirasa kurang tepat sasaran atau kurang mempengaruhi pembelian secara impulsif.

Bagi peneliti selanjutnya dapat memperbaiki dalam pengambilan sampel dan melakukan wawancara secara langsung terhadap responden supaya hasil penelitian lebih akurat.

Mengingat pengaruh variabel dari luar dikatan cukup besar, untuk peneliti selanjutnya dirasa perlu menambahkan beberapa variabel bebas seperti promo-promo yang sering dilakukan Alfamart. Seperti Coupon, Voucher, dan penataan In-store Display.

\section{DAFTAR PUSTAKA}

Badan Pusat Statistik (BPS). "Kecamatan Alam Barajo Dalam Angka 2019". diakses dari http://jambikota.bps.go.id/, diakses pada tanggal 29 Januari 2020 pada jam 20.00

Engel, James F., R. D Blackwell., dan P. W Miniard. 1995. Perilaku Konsumen. Jakarta: Binarupa Aksara.

Hartanto, A. Dan Haryanto, O.J. 2012. Pengaruh Display, Kepercayaan Merek, Keakraban Merek, Persepsi Harga Terhadap Intensi Pembelian dan Pembelian Tidak Terencana. Jurnal Manajemen, hal. 261-282.

Kotler, Philip, Gary Armstrong. 2010. Principles of Marketing (Edisi 13). United States of America: Pearson.

Ma'ruf, H. 2006. Pemasaran Ritel. Jakarta: PT Gramedia Pustaka Utama.

MA'RUF, I. K. 2013. Analisis Strategi Bauran Pemasaran Ritel Yang Menentukan Tingkat Kepuasan Konsumen Bravo Swalayan Tuban.Skripsi. Jurusan Manajemen Fakultas Ekonomi Dan Bisnis Universitas Brawijaya. Malang.

Putri, Y.T.A. dan Edwar, M., 2014.Pengaruh Bonus Pack dan Price Discount terhadap Impulse Buying pada Konsumen Giant Hypermarket Diponegoro Surabaya. Jurnal Manajemen Pemasaran.

Tjiptono, F. 2008. Strategi Pemasaran. Yogyakarta: Andi Offset.

Utami, C.W. 2010.Strategi dan Implementasi Ritel. Jakarta: Salemba Empat. 
Vicky, B.P. 2016. Pengaruh Price Discount dan Bonus Pack Terhadap Impulse Buying Pada Pelanggan Minimarket (Studi pada Pelanggan Minimarket Indomaret Jl. Demangan Baru, Depok, Sleman, Yogyakarta).Skripsi.Pada Fakultas Manajemen Universitas Negri Yogyakarta.Yogyakarta.

Waani, C.T. dan Alfa Tumbuan, J.F. 2015. The Influence Of Price Discount, Bonus Pack, And In-Store Display On Impulse Buying Decision In Hypermart Kairagi Manado. Jurnal EMBA, 3(3): 420-428.

Yusriyanti, A. 2008. Pengaruh In Store Promotion Terhadap Keputusan Impulse Buying Pada Konsumen Giant Hypermart. Skripsi.pada Fakultas Ekonomi dan Manajemen. Institut Pertanian Bogor. Bogor.

https://www.beecloud.id/jenis-jenis-bisnis-ritel-berdasarkan-klasifikasinya/ di unduh pada tanggal 16 Desember 2019

https://ekonomi.bisnis.com/read/20190107/12/876089/2019-bisnis-ritel-modern-ditargettumbuh-10di unduh pada tanggal 16 Desember 2019

http://corporate.alfamartku.com/pengembangan-sosial-kemasyarakatandi unduh pada tanggal 16 Desember 2019

http://www.wemarket.id/read/pilih-jambi-sebagai-cabang-ke-130-transmart-ini-alasan-pttrans-ritel-indonesia di unduh pada tanggal 22 Januari 2020 